\title{
HIV-1 LTR DNA sequence variation in brain-derived isolates
}

\author{
John R Corboy and Pamela J Garl \\ University of Colorado Health Sciences Center, Department of Neurology, Denver, Colorado, 80262, USA
}

\begin{abstract}
Isolates of human immunodeficiency virus (HIV-1) derived from the central nervous system (CNS) display properties distinctive from blood-derived isolates, including a high incidence of macrophage tropism in CNS isolates. Macrophage tropism is a result, in part, of DNA sequence variation in the HIV-1 envelope glycoprotein gene, but evidence also exists suggesting differences in the long terminal repeat (LTR) may contribute to differential gene expression. To investigate the nature of HIV-1 LTR sequence variation in the brain, we have sequenced bases -374 to +43 of the LTR from the brains of four HIV-1-infected patients. A total of 56 clones were derived from either both gray and white matter (three brains) or white matter alone (one brain), and these sequences were compared to 17 published sequences derived from multiple sources. A total of five LTR quasispecies were found. Overall, there was a significant amount of sequence variation both within and between brains, comparable to that seen in quasispecies of the envelope glycoprotein derived from blood or brain. The vast majority of the variation was seen in regions upstream from the two NF- $\kappa$ B sites. Compared to the blood-derived, T cell-tropic IIIB LTR, a majority of clones from two or more of the brains shared 11 unique substitutions in transcription factor binding sites, of which eight were shared with the CNSderived clones JR-CSF and JR-FL and altered the NF-AT and LEF-1 transcription factor binding sites. These findings correlate with published functional studies showing CNS-derived HIV-1 LTRs are distinct from the blood-derived IIIB LTR, and represent a starting point for future studies designed to determine which LTR sequence variations are associated with cellspecific differences in gene expression in the CNS.
\end{abstract}

Keywords: HIV-1; LTR; brain; AIDS dementia complex; transcription factor binding sites; viral tissue tropism

\section{Introduction}

The human immunodeficiency virus (HIV-1) invades the central nervous system (CNS) early after infection (Davis et al, 1992; Resnick et al, 1988), causing a slowly progressive dementia, the acquired immunodeficiency syndrome (AIDS) dementia complex (ADC), in $30-60 \%$ of patients (Atwood et al, 1993; McArthur et al, 1994; Navia et al, 1986). The relationship between intraparenchymal HIV-1 viral load, neuropsychological disease and HIV-1 associated neuropathological changes remains to be determined, but the available evidence supports the notion that HIV-1 viral load in the brain is associated with the clinical and neuropathological changes seen in AIDS patients (Achim et al, 1994; Böni et al, 1993; Brüstle et al,

Correspondence: JR Corboy

Received 19 February 1997; revised 12 June 1997; accepted 20 June 1997
1992; Epstein et al, 1987; Glass et al, 1995; Johnson et al, 1996; Masliah et al, 1992; Pang et al, 1991; Weiser et al, 1990; Wiley et al, 1996). Isolates of HIV-1 from the CNS display properties which distinguish them from peripheral blood isolates, such as relative inability to infect $\mathrm{T}$ lymphocyte cell lines, efficient replication in macrophages and microglia, and reduced cytopathogenicity (Anand et al, 1987; Cheng-Mayer et al, 1989), suggesting CNS isolates may represent a separate subgroup of HIV-1. The regions of the HIV-1 viral genome important for CNS tissue tropism and disease potential have not been completely defined. The cells in the CNS most commonly found to be infected by HIV-1 are macrophages and microglia (Koenig et al, 1986; Wiley et al, 1986), and most of the quasispecies derived from the central nervous system (CNS) display macrophage tropism (Cheng-Mayer et al, 1990; Cheng-Mayer et al, 1989; Korber et al, 1994; 
Koyanagi et al, 1987; Liu et al, 1990; O’Brien et al, 1990; Sharpless et al, 1992; Watkins et al, 1990). Macrophage tropism has been ascribed to DNA sequence variations in the V3 loop and possibly other regions of the envelope glycoprotein, gp120 (Boyd et al, 1993; Cann et al, 1992; Cheng-Mayer et al, 1990; Chesebro et al, 1992; Groenink et al, 1992; Hwang et al, 1991; Korber et al, 1994; Liu et al, 1990; O’Brien et al, 1990; Sharpless et al, 1992; Shimizu et al, 1994; Shioda et al, 1991), encoded by the env gene. Although there have been reports suggesting signature amino acid sequences exist in HIV-1 gp120 variants in the CNS (Korber et al, 1994), or that one or more amino acid substitutions in the V3 loop discriminate between patients with and without ADC (Power et al, 1994), these findings have not been reproduced (Kuiken et al, 1995).

The long terminal repeat (LTR), where the promoter and enhancer regions of the virus are located, might also contribute to tissue tropism. As with the HIV-1 env gene (Ball et al, 1994; Epstein et al, 1991; Korber et al, 1994; Pang et al, 1991), HIV-1 LTR DNA sequences appear to evolve independently in the CNS (Ait-Khaled et al, 1995). In other retroviruses, variant LTR sequences have been associated with tissue tropism and disease potential (Celander and Haseltine, 1984; Lenz et al, 1984; Rosen et al, 1985; Small et al, 1989), sometimes in association with the env gene (Poliquin et al, 1992; Portis et al, 1990; Yuen et al, 1986). Some groups have found cell type-specific differences in replication or gene expression in association with various substitutions, additions or deletions within the HIV1 LTR (Delassus et al, 1991; Golub et al, 1990; Kim et al, 1993; Koken et al, 1992; Michael et al, 1994; Tillman et al, 1994; Zeichner et al, 1992), while others have not (Pomerantz et al, 1991). We previously showed the LTRs of strains JR-CSF and JR-FL, derived from the cerebrospinal fluid (CSF) and frontal lobe, respectively, of a patient with ADC (Koyanagi et al, 1987), are able to direct the expression of a reporter gene in the CNS of transgenic mice, whereas the blood-derived, $\mathrm{T}$ cell-tropic strain HIV IIIB LTR is not (Corboy et al, 1992). Subsequent studies of in utero, neonatal and adult mice constructed with the JR-FL and JR-CSF LTRs revealed CNS expression in these transgenic mice varies by location and cell type over time (Buzy et al, 1995), which may be relevant to the clinical and neuropathological differences seen between adult and pediatric HIV-1 patients (Sharer, 1992).

Recent studies have attempted to determine which regions within the LTR might contribute to tissue- and cell-specific gene expression within the CNS. Using DNA footprint analysis and electrophoretic mobility shift assays (EMSAs), CannoneHergaux et al (1995) found nuclear extracts from cultured astrocytic (U-373 MG), neuronal (SK-N-
MC) and T lymphocytic cells (Jurkat) bound with different affinities the JR-FL, JR-CSF and LAI (IIIB) LTRs in the region -352 to -324 . Further, variant sequences encompassing an AP1 site in both neurotropic strains, in the region -247 to -222 , could bind U-373 MG extracts, but not those from SK-N-MC or Jurkat cells, and this variant sequence was able to mediate AP1-induced transcriptional activation in U-373 MG but not SK-N-MC or Jurkat cells. In contrast, Kurth et al (1996) detected binding in the region -300 to -260 using an in vivo DNA footprinting analysis with brain extracts of transgenic mice expressing JR-CSF, and brain extracts of nontransgenic newborn mice were able to bind region -296 to -256 of JR-CSF but not IIIB LTR. Finally, studies with linker scanning mutants of the HIV-1 LTR transfected into the neuron-like NTERA cells have revealed two upstream regions $(-219$ to -202 and -255 to -238$)$ important for cell-specific gene expression (Zeichner et al, 1992).

Thus, HIV-1 LTR quasispecies may evolve independently within the CNS, and may be associated with cell- and tissue-specific nuclear extract binding and gene expression. Which regions of the LTR have greatest importance in the CNS remain unclear. In order to define further the spectrum of sequences potentially relevant to HIV-1 gene expression in the CNS, we analyzed HIV-1 LTR DNA isolated from the brains of four HIV-1-infected adult patients. The sequences were aligned and compared by phylogenetic analysis to themselves (intra-brain and inter-brain), the CNS-derived clones described by Ait-Khaled et al (1995), and to 16 previously published LTR sequences deposited in the Los Alamos HIV-1 sequence databank (Myers et al, 1995).

\section{Results}

Comparisons within brains, between brains and to published clones

DNA was amplified, cloned and sequenced from a total of seven sections of four brains: from gray and white matter of three brains, and white matter alone of one brain. All 56 sequences fit into clade $B$ of sequences entered in the Los Alamos AIDS sequence databank (Myers et al, 1995). A sequence homology and phylogenetic analysis of bases -374 to +43 of the LTR revealed a range of $85.4-100 \%$ sequence similarity within any one brain, with the weighted mean of $96.4 \%$. Three of the brains $(2627,2297,2135)$ had two distinct quasispecies, and one (2444) had one, or possibly two. Two of the three brains from which both gray and white matter clones were sequenced (2135, 2627) had a quasispecies common to both gray and white matter, and a second quasispecies seen only in the white (2627) or gray (2135) matter. The third brain (2444) had a gradient of sequence similarity, with the white and gray matter sub- 


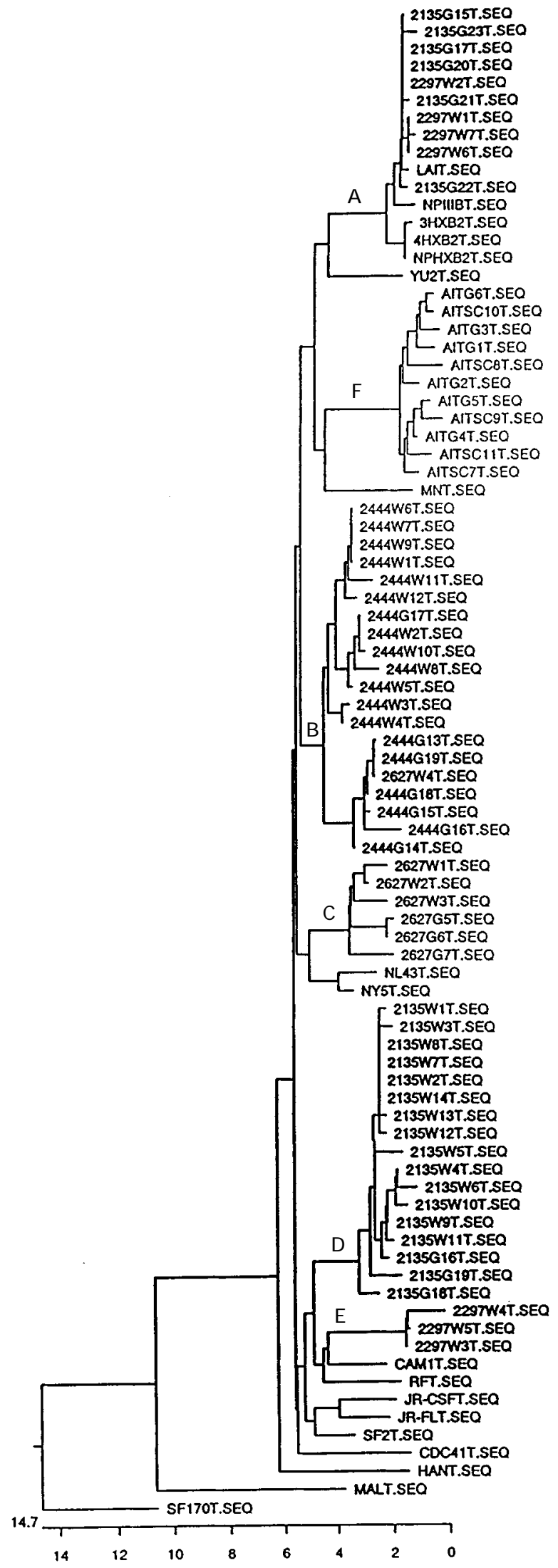

groups in group B (Figure 1) possibly representing separate quasispecies. The brain represented by white matter clones alone (2297) displayed two quasispecies, one of which was shared with brain 2135. Sequence similarity between clones from different brains ranged from $85.2-100 \%$ per clone, with a mean of $92.8 \%$. Thus, overall there were at least five distinct populations of sequences, or, quasispecies (A-E), as seen in Figure 1. The 16 comparable LTR sequences (Figure 1) in clade B of the Los Alamos HIV-1 sequence database (Myers et al, 1995), derived from multiple tissues and sources, shared 93\% similarity with one another, and with our brain clones. When placed on our phylogenetic tree, the sequences described by Ait-Khaled et al (1995), derived from spinal cord and dorsal root ganglia of a single patient, occupied a branch (group F) separate from our clones and equally distant from IIIB, JR-FL and JR-CSF.

Variation within transcription factor binding sites A simplified scheme of agreed-upon transcription factor binding sites within the HIV-1 LTR (Gaynor, 1992) is shown in Figure 2. These sites encompass $55 \%$ of all bases within the range of amplified LTR in these sequences. Of the 120 positions at which any of our brain clones differed from the consensus of the brain clones, 65 (54\%) occurred within transcription factor binding sites. This was true whether the substitution was rare or common. Substitutions, additions or deletions were rare, however, within the three Sp1 sites and the two $\mathrm{NF}-\kappa \mathrm{B}$ sites, and the brain consensus sequence was identical to the clade B consensus in these areas. Similarly, there were few alterations from the clade $\mathrm{B}$ consensus in the TATA region, UBP regions, or in that portion of the TAR region we amplified. There was much greater diversity within the NF-AT, LEF1 COUP, and USF transcription factor binding sites, in comparison to the brain consensus, the clade B consensus, and IIIB (Figure 2).

Figure 1 Phylogenetic tree of brain-derived HIV-1 LTRs. Phylogenetic tree comparing bases -374 to +43 of the HIV-1 LTR in 56 brain-derived clones to spinal cord and dorsal root ganglia clones from Ait-Khaled et al (1995), and to IIIB, HXB2, JR-CSF, JR-FL, CAM, CD41, HAN, LAI, MAL, MN, NL43, NY5, RF, SF170, SF2 and YU2 (Myers et al, 1995). The 'T' at the end of each sequence denotes that these are sequences truncated to include only bases -374 to +43 . 'NP' before the IIIB and HXB2 sequences denote that these sequences are taken from DNA which was not PCR-amplified. '3HXB2' and '4HXB2' are two clones which were PCR-amplified from plasmid DNA, and which are identical to the 'NPHXB2'. This unrooted, unbalanced tree is obtained using the neighbor-joining method (Saitou and Nei, 1987). The length of each pair of branches represents the distance between sequence pairs. The scale beneath the tree measures the distance between sequences, and the units indicate the number of substitution events. The capital letters A-F denote the presumed quasispecies. 
HIV-1 LTR, CLONE IIIB

COUP

AP1 COUP
-374 TTAGCAGAAC TACACACCAG GGCCAGGGGT CAGATATCCA CTGACCTTTG -325
G
$!$
g
a
aa
T
$t$
$\underline{\mathrm{NE}-\mathrm{AT}}$
-324 GATGGTGCTA CAAGCTAGTA CCAGTTGAGC CAGATAAGGT AGAAGAGGCC -275

$\begin{array}{cccc} & T & t & G / A \\ & ! & & ! !\end{array}$
$-274 \overline{\text { AATAAAGGAG AGAACACCAG }}$ CTTGTTACAC CCTGTGAGCC TGCATGGAAT -225

G A T
A
!
! *
!
A $\quad$ g

NF-AT

-224 GGATGACCCT GAGAGAGAAG TGTTAGAGTG GAGGTTTGAC AGCCGCCTAG -175
a $\mathrm{G} / \mathrm{C}$
G/A AG
a
AAG

!

$t$

USF

LEF-1 ATF / CREB

-174 CATTTCATCA CGTGGCCCGA GAGCTGCATC

g

ATE / CREB

-124 TGACATCGAG

c
$\underline{N E-K B}$

GGGACTTTCC

TC

! ! !

$\operatorname{Sp} 1$ (2)

Sp1 (1)

TBP

-74 GCGTGGCCTG GGCGGGACTG GGGAGTGGCG AGCCCTCAGA TGCTGCATAT -25

1

UBP-1 U3 $\quad$ U3 R

-24 AAGCAGCTGC TTTTTGCCTG TACTGGGTCT CTCTGGTTAG ACCAGATCTG +24

\section{UBP-2 \\ +25 AGCCTGGGAG CTCTCGG +43}

Figure 2 HIV-1 LTR, clone IIIB. Bases -374 to +43 of clone IIIB LTR, with agreed upon trascription factors (Gaynor, 1992) shown above the DNA motifs to which they bind (note overlap of LEF-1 and ATF/CREB sites). Sites at which both JR-FL and JR-CSF differ from IIIB (JR substitution sites) are noted in bold, upper-case letters below the sequence, with lower-case letters representing substitutions in either JR-CSF or JR-FL. Also marked below the IIIB sequence are those positions at which 14 or more $\left(^{*}\right)$ or 28 or more (!) of our 56 brain clones (in at least two of the four brains) differ from IIIB. Substitutions in our brain clones at JR substitution sites are identical to the JR substitutions. The transcription factor binding sites are indicated by the first letter of the name at the $5^{\prime}$ end, and the end of the underline at the 3' end. Abbreviations: COUP, Chicken Ovalbumin Upstream Promoter; AP1, Activating Protein 1; NF-AT, Nuclear Factor of Activated T cells; USF, Upstream Stimulatory Factor; LEF-1, Lymphocyte Enhancer Factor-1; ATF/CREB, Activating Transcription Factor/cAMP Response Element Binding; NF- $\kappa$ B, Nuclear Factor- $\kappa$ B; Sp1, SV40 Promoter 1; TBP, TATA Binding Protein; UBP, Untranslated Binding Protein. Note that not all DNA motifs conform to consensus descriptions, as some HIV-1 clones are variable in these regions. 
We have already shown HIV-1 IIIB LTR does not, while the CNS-derived clones JR-FL and JR-CSF do, drive expression of a reporter gene in the CNS of transgenic mice (Corboy et al, 1992). This functional difference presumably is related to differences in the DNA sequences of the LTRs. From bases -374 to +43 of the LTR, there are 21 base pair differences distinguishing IIIB from both JR-FL and JR-CSF (Figure 2). These differences are referred to here as JR substitutions. Clones in group A (Figure 1) shared 4-7 JR substitutions, while sequences in group B-E shared 10-17 JR substitutions.

Eleven of 21 (52\%) JR substitutions fell within transcription factor binding sites, seven within the two designated NF-AT motifs (positions - 292 to -255 and -215 to -203 ), three within the LEF-1 site $(-139$ to -124$)$ and one within the COUP site (Figure 2). Thus, although the NF-AT transcription factor binding sites constitute just $12 \%$ of the total amplified LTR $33 \%$ of all JR substitutions occurred within these sites. At eight of the $11 \mathrm{JR}$ substitution locations within transcription factor binding sites, including five in the NF-AT and three in LEF-1 binding sites, a majority of our brain clones shared the exact JR substitution (Figure 2).

There also were six JR substitution sites outside of the agreed-upon transcription factor binding sites at which a majority of our brain clones shared the same JR substitution. Overall, at a total of 14 JR substitution sites, a majority of our brain clones were identical to the JR substitution. Among the published sequences noted in Figure 1 (total of 14, excluding HXB2 and the two JR clones, and using the consensus of the clones from $\{2\})$, the number of JR substitutions shared was as few as four (LAI) and many as 19 (SF2), with a mean of 13.8. On average, 8.6 of the 14 clones compared above shared any one JR substitution. There was no correleation of macrophage-tropic or T cell-tropic strains of HIV-1 with number of JR substitutions in that clone.

In addition to JR substitutions shared by a majority of our clones, there also were eight other locations at which a majority of our brain-derived clones differed from IIIB. At three of these locations, either JR-FL or JR-CSF differed from IIIB, and at five both JR clones were the same as IIIB. Just three of these other locations were within transcription factor binding sites (NF-AT, LEF-1 and Sp1), but three occurred very near one another, between bases -198 and -192 . Therefore, there were a total of 11 locations within transcription factor binding sites at which a majority of our clones differed from IIIB, eight of which were shared by the JR clones. Of the 14 comparison clones noted above, an average of 9.3 of these clones also shared the substitutions that distinguished our clones from IIIB.

\section{Multiplication of ATF/CRE transcription factor binding sites}

Recently, an ATF/CREB site was identified just upstream from the two NF- $\kappa$ B sites in the HIV-1 LTR derived from multiple blood samples, and was shown to bind ATF/CREB factors derived from U-373 MG astrocytic cells (Krebs et al, 1997). Analysis of our brain-derived sequences, all 16 of the comparable clones in the Los Alamos HIV-1 sequence database (45-Figure 1), and the clones described by Ait-Khaled et al (1995)

\section{ATF/CREB DUPLICATIONS}

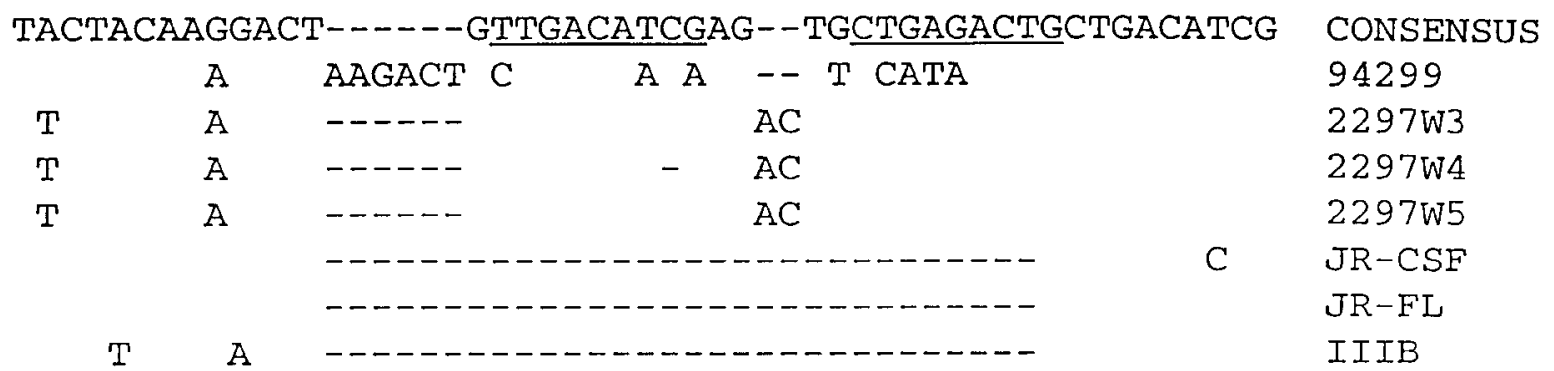

IEF-1

Figure 3 ATF/CREB duplications. Three brain-derived and one blood-derived (94299) sequences are aligned with bases - 139 to - 117 of IIIB, JR-FL, and JR-CSF, revealing 23-28 bp insertions creating one or two extra putative ATF/CRE transcription factor binding sites (CTGACAT/CCG, Krebs, et al, unpulbished data). These insertions interrupt the LEF-1 site. The consensus sequence represents the majority bases of the seven sequences listed. The extra six bases at the $5^{\prime}$ end of clone 94299 recapitulates, in part, the LEF-1 site. The two putative ATF/CRE duplications are underlined in the consensus sequence. 
and Estable et al (1996) revealed little overall variation within this ATF/CREB site. In brain sample 2297, we sequenced three clones with an apparent extra two ATF/CREB sites embedded in $23-24 \mathrm{bp}$ insertions at position -126 (Figure 3 ). These insertions interrupted the LEF-1 site, and were similar in location and DNA sequence to the LEF-1 duplications described in blood samples by others (Ait-Khaled et al, 1995; Delassus et al, 1991; Estable et al, 1996; Golub et al, 1990; Michael et al, 1994). The insertions differed from each other at only a single base, and shared 15 bases with the $28 \mathrm{bp}$ insertion in clone, 94299, derived from the blood of an unrelated patient (Figure 3).

\section{Discussion}

In this study, we describe the amount and the location of DNA sequence variation in HIV-1 LTR sequences derived from the brains of four HIV-1infected patients. The degree of sequence variation in the env region in brain samples has varied widely, from as little as $2.1 \%$ differences between brains (Monken et al, 1995) to a maximum of $11.8 \%$ (Korber et al, 1994). Variation in env may be somewhat less in brain than blood samples, suggesting either a lack of divergence or a convergence to macrophage-tropism among HIV-1 env sequences derived from the brain (Korber et al, 1994). Within a single brain, Korber et al (1994) found significantly fewer sequence differences in the env region with respect to comparisons made between brains $(3.5 \%$ vs $11.8 \%)$. In our brain samples we found $96.4 \%$ sequence similarity $(3.6 \%$ difference) within a brain sample and $92.8 \%(7.2 \%$ difference $)$ between brain samples. Thus, the amount of sequence variation in our brain-derived LTR samples is comparable to the variation in brain-derived env sequences.

In this study, we can not determine whether any particular HIV-1 LTR sequence is associated with ADC or other neurological syndromes. It is interesting to note, however, the patient described by Ait-Khaled et al (1995) had vacuolar myelopathy without ADC, and the clones derived from the spinal cord and dorsal root ganglia of this patient were quite different from our brain-derived clones, although they shared 15 JR substitutions. Thus, there may be variation in the HIV-1 LTR which is relevant to location-specific viral replication within the CNS. It also is possible that had Ait-Khaled et al (1995) obtained sequences from more than one patient, there might have been greater overlap with our brain-derived clones.

The substitutions in the LTR described here, whether in comparison to the consensus of all the brain sequences or to the clade B consensus, were not random. Similar to other reports of brainderived (Pomerantz et al, 1991) and some blood- derived LTR sequences (Estable et al, 1996; Krebs et al, 1997), we found very few alterations in both $\mathrm{NF}-\kappa \mathrm{B}$ sites, two of three Sp1 sites, the ATF/CREB sites and the TAR regions, suggesting these sites are necessary for transcription to function properly in the brain. Others, looking primarily at clones derived from blood or peripheral blood mononuclear cells, have identified more significant changes within the NF- $\kappa \mathrm{B}, \mathrm{SP}-1$ and TAR bindings sites. (Ait-Khaled et al, 1995; Delassus et al, 1991; Koken et al, 1992; McNearney et al, 1995).

The majority of variation in our brain samples was upstream of the second NF- $\kappa \mathrm{B}$ binding site, many of the changes altering transcription factor binding sites in what has been termed the negative regulatory element (NRE). The NRE encompasses the NF-AT and USF binding sites, and has potential repressor and activator functions (Gaynor, 1992; Lu et al, 1990; Orchard et al, 1990; Rosen et al, 1985). A disproportionate number of JR substitutions occurred within the two NF-AT binding sites (especially the upstream site at nucleotides -292 to -255), and many of our brain clones and other published clones from the CNS (Ait-Khaled et al, 1995; Li et al, 1992) and other tissues shared these substitutions. The JR substitutions changed the NFAT binding site from -292 to -255 at multiple positions, potentially altering transcription significantly in different cells. Further suggesting the importance of this region were the recent findings of Kurth et al (1996), in which the region -296 to -256 of the JR-CSF LTR was able to bind brainderived nuclear proteins, while the highly $\mathrm{T}$ celltropic IIIB LTR in the same region was not. The transfection studies of Zeichner et al (1992), show sequence variation at the other NF-AT site, -219 to -202 , a region in which many of our clones share JR substitutions, is associated with differential gene expression in the neuron-like NTERA cells, but binding studies have not yet shown this area to be important in neural cells.

Changes in the LEF-1 transcription factor binding site have the same potential for affecting transcription. Six of the sites at which a majority of our brainderived LTR clones differed from IIB fell between positions -201 and -130 , a region in which DNA substitutions have been associated with significantly lowered transcriptional activity in $\mathrm{T}$ cells (Kim et al, 1993). This confluence of brain-derived LTR sequences sharing specific substitutions within the NF-AT, USF and LEF-1 sites strongly suggests these changes result in altered HIV-1 gene expression in T cells, and may, in part, explain why many brain-derived clones are macrophage-tropic.

In a related study (Krebs et al, unpublished data) using electrophoretic mobility shift assays, we have analyzed the effect that multimerization of the ATF/ CREB site has on the ability to bind nuclear extracts from cells of astrocytic (U-373 MG) and T lympho- 
cyte (Jurkat) origin. The oligonucleotide probe representing the multimerized ATF/CREB site in clone 2297w3 (Figure 3), when reacted with nuclear extract from Jurkat cells, produced DNA-protein complexes which were different in abundance and mobility compared to complexes produced with the same probe but nuclear extracts from the U-373 MG cells (data not shown). The differences in complex formation between these two cell types suggest differences in factor recruitment and site occupation, and provide another mechanism by which different LTR quasispecies may produce functional alterations in transcription capabilities in different cells in the CNS and elsewhere.

In comparing a number of published LTR sequences to IIIB, the JR clones and our brainderived clones, it is clear clones derived from a number of sources share varying amounts of sequence similarity with our brain-derived clones. There is no simple correlation, however, between sharing a large number of JR substitutions and $\mathrm{T}$ cell-tropism or macrophage-tropism. For example, clone SF2, initially obtained by cocultivation from peripheral blood mononuclear cells, is T cell-tropic (Cheng-Mayer et al, 1989) yet shares 19 of 21 JR substitutions in the LTR. This suggests several possibilities. First, with the exception of disturbances in the core promoter and enhancer regions (e.g. TATA, Sp1 and NF- $\kappa$ B sites), variation in the LTR might be meaningless, especially with regard to differential gene expression within the brain. The functional data described above strongly argues against this. Second, some LTR sequences may represent clones which recently entered the CNS, while others might represent species which have been present in the CNS for a longer period of time, and which have evolved independently from the blood, as suggested by Ait-Khaled et al (1995). Without blood samples from the same patients, we can not answer this question directly. The third possibility is HIV-1 infects multiple different cells in the brain, and viral strains display a range of abilities to replicate within the various cells. The cells in the CNS which most commonly are found to be productively infected by HIV-1 are macrophages and microglia (Koenig et al, 1986; Wiley et al, 1996), explaining why most CNS-derived strains of HIV-1 are macrophage-tropic. But recent evidence shows astrocytes (Saito et al, 1994; Takahashi et al, 1996; Tornatore et al, 1994) and neurons (Bagasra et al, 1996; Nuovo et al, 1994) also are infected, albeit at a lower level. Thus it is possible that CNS-derived isolates of HIV-1 may have tropism for one or more of several cell types. Changes in the LTR could be associated with differences in transcriptional function in different cells, which might, in part, account for the relative difficulty in obtaining evidence of HIV-1 infection in neural cells. This also might explain why some HIV-1 isolates obtained from blood (Cheng-Mayer et al, 1989) or CSF (Koyanagi et
Table 1 HIV-1 LTR primers for PCR and DNA sequencing primer

\begin{tabular}{lrlr}
\hline Name & \multicolumn{3}{c}{ Primer } \\
\hline A & -452 & 5' GGAAGGGCTAATTCACTCACAG 3' & -431 \\
B & +123 & 3' ACTGAGACCATTGATCTCTAG 5' & +145 \\
C & -395 & 5' CACACAAGGCTACTTCCCTGA 3' & -375 \\
D & +44 & 5' GATTGATCCCTTGGGTGACG 3' & +63 \\
E & -9 & 5' GCCTGTACTGGGTCTCTCTGG 5 & +11 \\
\hline
\end{tabular}

al, 1987) are $\mathrm{T}$ cell-tropic, yet are relatively more able to infect cells of astrocytic origin than are macrophage-tropic isolates. Future studies with our brain-derived clones will address questions regarding the nature of virus-host cell interaction in cells relevant to the CNS.

\section{Materials and methods}

The right halves of brains from HIV-infected adult patients from New York and Minneapolis were collected at autopsy, 6-48 h after death, and fresh frozen. Approximately $0.5 \mathrm{~cm} \times 0.5 \mathrm{~cm} \times 0.5 \mathrm{~cm}$ pieces of right frontal gray and subcortical white matter were chipped from each brain using a sterile, disposable scalpel, taking care to minimize exposure to blood components. The pieces were chopped with the scalpel, pulverized in a disposable $1.5 \mathrm{ml}$ plastic tube with a disposable pestle, and treated with proteinase $\mathrm{K}(50 \mu \mathrm{g} / \mathrm{ml})$ in $1 \%$ SDS, $50 \mathrm{mM}$ Tris (pH 8.0), $100 \mathrm{mM}$ EDTA, and $100 \mathrm{mM} \mathrm{NaCl}$ overnight with shaking at $55^{\circ} \mathrm{C}$. The mixture was treated with RNAse A, $1 \mu \mathrm{g} / \mathrm{ml}$, at $37^{\circ} \mathrm{C}$ for $30 \mathrm{~min}$, extracted with phenol, phenol/chloroform and chloroform, precipitated with $100 \%$ ethanol and $0.3 \mathrm{M}$ NaAcetate, washed with $70 \%$ ethanol, dried, resuspended in TE 8.0 and quantitated. One $\mu \mathrm{g}$ of genomic DNA was used as a template for polymerase chain rection (PCR) using GAPDH primers, to determine if the DNA was intact.

Portions of the HIV-1 LTR were amplified by PCR using either primers $A$ and $B, C$ and B, or a nested set of primers, $A$ and $B$, followed by $C$ and $\mathrm{D}$ (Table 1). Those portions of the LTR used as primers were identical in the IIIB, JR-CSF and JRFL clones. One or two rounds of PCRs were used to derive all of the sequences from each brain section. Amplification consisted of 35 cycles of $60 \mathrm{~s}$ at $94^{\circ} \mathrm{C}, 45 \mathrm{~s}$ at $55-59^{\circ} \mathrm{C}$ and $60 \mathrm{~s}$ at $72^{\circ} \mathrm{C}$, followed by one cycle for $7 \mathrm{~min}$ at $72^{\circ} \mathrm{C}$. The $40 \mu \mathrm{L}$ reaction mixture contained $1 \mu \mathrm{g}$ of genomic DNA, $80 \mu \mathrm{M}$ of each primer and $20 \mathrm{mM}$ each of dATP, dCTP, dGTP and dTTP in $10 \mathrm{~m}$ Tris, $1.5 \mathrm{mM} \mathrm{MgCl}_{2}$ and $50 \mathrm{mM} \mathrm{KCl}$. PCR products were ligated into a TA cloning vector (Invitrogen) overnight, $E$. coli $\mathrm{INV}_{\alpha \mathrm{F}^{\prime}}$ cells were transformed with the ligation mix, and miniprep DNA was 
prepared (BIO-RAD). After a diagnostic restriction digest, the DNA was sequenced manually with the chain termination technique using Sequenase T7 DNA polymerase (Amersham), primers $\mathrm{T} 7$ and SP6, and an internal primer, E (Table 1), from the LTR. An overall error rate of one base per 1$5 \times 10^{5}$ bases was determined by amplifying and sequencing analogous sequences of known plasmid DNA.

The sequences were read manually and entered into a Compaq Prolinea 4/50 computer for phylogenetic analysis by the Lasergene software (DNASTAR). For purposes of this discussion, the term quasispecies is defined as a population of closely related genomes, apparently derived from a common progenitor (Delassus et al, 1991; Goodenow et al, 1989). Clones were named by the brain from which they were derived, a designation for white or gray matter ( $w$ or g, respectively), and a sequential clone number from that brain, e.g. 2135W1, $2135 \mathrm{~W} 2$, etc. The ' $\mathrm{t}$ ' after each sequence refers to

\section{References}

Achim CL, Wang R, Miners DL, Wiley CA (1994). Brain viral burden in HIV infection. J Neurolpathol Exp Neurol 53: 284-294.

Ait-Khaled M, McLaughlin JE, Johnson MA, Emery VC (1995). Distinct HIV-1 long terminal repeat quasispecies present in nervous tissues compared to that in lung, blood and lymphoid tissues of an AIDS patient. AIDS 9: $675-683$.

Anand R, Reed C, Forlenza S, Siegal F, Cheung T, Moore J (1987). Non-cytocidal natural variants of human immunodeficiency virus isolated from AIDS patients with neurological disorders. Lancet 2: 234-238.

Atwood WJ, Berger JR, Kaderman R, Tornatore CS, Major EO (1993). Human immunodeficiency virus type 1 infection in the brain. Clin Microbiol Rev 6: 339-366.

Bagasra O, Lavi E, Bobroski L, Khalili K, Pestaner JP, Tawadros R, Pomerantz RJ (1996). Cellular reservoirs of HIV-1 in the central nervous system of HIV-1infected-individuals: identification by the combination of in situ polymerase chain reaction and immunohistochemistry. AIDS 10(6): 573-585.

Ball JE, Holmes EC, Whitwell H, Desselberger U (1994). Genomic variation of human immunodeficiency virus type 1 (HIV-1): molecular analyses of HIV-1 in sequential blood samples and various organs obtained at autopsy. J Gen Virol 75: 867-879.

Böni J, Emmerich BS, Leib SL, Wiestler OD, Schupbach J, Kleihus P (1993). PCR identification of HIV-1 DNA sequences in brain tissue of patients with AIDS encephalopathy. Neurology 43: 1813-1817.

Boyd MT, Simpson GR, Cann AJ, Johnson MA, Weiss RA (1993). A single amino acid substitution in the V1 loop of human immunodeficiency virus type 1 gp120 alters cellular tropism. J Virol 67: $3649-3652$.

Brüstle O, Spiegel H, Leib SL, Finn T, Stein H, Kleihues P, Wiestler OD (1992). Distribution of human immunodeficiency virus (HIV) in the CNS of children with severe HIV encephalomyelopathy. Acta Neuropathol 84: 24-31. the fact that these sequences are truncated, and do not include the primers used to amplify them.

\section{Acknowledgements}

This work was supported by Public Health Service Grant 5KO8 NS01673-04 (to JRC) from the National Institute of Neurological Disorders and Stroke. We acknowledge Dr Richard Price for allowing access to stored autopsy material, $\mathrm{Mr}$ Randall Thompson and Dr Randall Cohrs for technical assistance, Dr Donald Gilden for valuable discussions of the project, and Ms Jane David for secretarial support. The IIIB clone was a gift from Dr Robert Gallo, while JR-CSF and JR-FL were received from Dr. Irvin Chen. Ms Mary Rosandich and Dr Robert Schooley supplied the DNA from cultured blood which resulted in sequence 94299.

Buzy JM, Lindstrom LM, Zink C, Clements JE (1995) HIV-1 in the developing CNS: developmental differences in gene expression. Virology 210: $361-$ 371.

Cann AJ, Churcher MJ, Boyd M, O’Brien W, Zhae J, Chen ISY (1992). The region of the envelope gene of human immunodeficiency virus type 1 responsible for determination of cell tropism. J Virol 66: 305-309.

Canonne-Hergauz F, Aunis D, Schaffer E (1995). Interactions of the transcription factor AP-1 with the long terminal repeat of different human immunodeficiency virus type 1 strains in jurkat, glial, and neuronal cells. J Virol 69: 6634-6642.

Celander D, Haseltine WA (1984). Tissue-specific transcription preference as a determinant of cell tropism and leukaemogenic potential of murine retroviruses. Nature 312: 159-162.

Cheng-Mayer E, Quiroga M, Tung JW, Dina D, Levy JA (1990). Viral determinants of human immunodeficiency virus type 1 T-cell or macrophage tropism, cytopathogenicity, and CD4 antigen modulation. J Virol 64: 4390-4398.

Cheng-Mayer D, Weiss C, Seto D, Levy JA (1989). Isolates of human immunodeficiency virus type 1 from the brain may constitute a special group of the AIDS virus. Proc Natl Acad Sci USA 86: 8575-8579.

Chesebro D, Wehrly K, Hishio J, Perryman S (1992). Macrophage-tropic human immunodeficiency virus isolates from different patients exhibit unusual V3 envelope sequence homogeneity in comparison with T-cell tropic isolates: Definition of critical amino acids involved in cell tropism. J Virol 66: 6547-6554.

Corboy JR, Buzy JM, Zink MC, Clements JE (1992). Expression directed from HIV long terminal repeats in the central nervous system of transgenic mice. Science, 258: 1804-1808. 
Davis LE, Hjelle BL, Miller VE, Palmer DL, Llewellyn AL, Merlin TL, Young SA, Millis RG, Wachsman W, Wiley CA (1992). Early viral brain invasions in iatrogenic human immunodeficiency virus infection. Neurology 42: 1736-1739.

Delassus S, Cheynier R, Wain-Hobson S (1991). Evolution of human immunodeficiency virus type 1 $n e f$ and long terminal repeat sequences over 4 years in vivo and in vitro. J Virol 65: 225-231.

Epstein LG, Goudsmit J, Paul DA, Morrison SH, Connor EM, Oleske JM, Holland B (1987). Expression of human immunodeficiency virus in cerebrospinal fluid of children with progressive encephalopathy. Ann Neurol 21: 397-401.

Epstein LG, Kuiken C, Blumberg BM, Hartman S, Sharer LR, Clement M, Goudsmit J (1991). HIV-1 V3 domain variation in brain and spleen of children with AIDS: tissue-specific evolution within host-determined quasispecies. Virology 180: $583-590$.

Estable MC, Bell B, Merzouki A, Montaner JSG, O'Shaughnessy MV, Sadowski IJ (1996). Human immunodeficiency virus type 1 long terminal repeat variants from 42 patients representing all stages of infection display a wide range of sequence polymorphism and transcription activity. $J$ Virol 70: $4053-4062$.

Gaynor R (1992). Cellular transcription factors involved in the regulation of HIV-1 gene expression. AIDS 6: $347-363$.

Glass JD, Fedor H, Wesselingh SL, McArthur JC (1995) Immunocytochemical quantitation of human immunodeficiency virus in the brain: correlations with dementia. Ann Neurol 38: 755-762.

Golub EI, Li G, Volsky DJ (1990). Differences in the basal activity of the long terminal repeat determine different replicative capacities of two closely related human immunodeficiency virus type 1 isolates. J Virol 64: $3654-3660$.

Goodenow MM, Huet T, Saurin W, Kwok S, Sninsky J, Wain-Hobson S (1989). HIV-1 isolates are rapidly evolving quasispecies: evidence for viral mixtures and preferred nucleotide substitutions. J Acquir Immune Defic Syndr Hum Retrovirol 2: 344-352.

Groenink M, Andeweg AC, Fouchier AM, Broersen SM, Van Der Jagt RC, Schuitemaker H, De Goede REY, Rosch ML, Hisman HG, Tersmette M (1992). Phenotype-associated env gene variation among eight related human immunodeficiency virus type 1 clones: evidence for in vivo recombination and determinants of cytotropism outside the V3 domain. I Virol 66: $6175-6180$

Hwang SS, Boyle TJ, Lyerly HK, Cullen BR (1991). Identification of the envelope V3 loop as the primary determinant of cell tropism in HIV-1. Science 253: $71-74$

Johnson RT, Glass JD, McArthur JC, Chesebro BW (1996). Quantitation of human immunodeficiency virus in brains of demented and nondemented patients with acquired immunodeficiency syndrome. Ann Neurol 39: $392-395$.

Kim JYH, Gonzalez-Scarano F, Zeichner SL, Alwine JC (1993). Replication of type 1 human immunodeficiency viruses containing linker substitution mutations in the -201 to -130 region of the long terminal repeat. J Virol 67: 1658-1662.
Koenig S, Gendelman HE, Orenstein JM, Dal Canto MC, Pezeshkpour GH et al. (1986). Detection of AIDS virus in macrophages in brain tissue from AIDS patients with encephalopathy. Science 233: 1089-1093.

Koken SEC, VanWamel JLB, Goudsmit J, Berkhout B, Geelen JLMC (1992). Natural variants of the HIV-1 long terminal repeat: analysis of promoters with duplicated DNA regulatory motifs. Virology 191: 968-972.

Korber BTM, Kunstman KJ, Patterson BK, Fertado M, McEvilly MM, Levy R, Wolinsky AM (1994). Genetic differences between blood- and brain-derived viral sequences from human immunodeficiency virus type 1-infected patients: evidence of conserved elements in the $\mathrm{V} 3$ region of the envelope protien of brain-derived sequences. J Virol 68: 7467-7481.

Koyanagi Y, Miles S, Mitsuyasu TR, Merrill JE, Vinters HV, Chen ISY (1987). Dual infection of the cnetral nervous system by AIDS viruses with distinct cellular tropisms. Science 236: 819-822.

Krebs FC, Goodenow MM, Wigdahl B (1997). Neuroglial ATF/CREB factors interact with the human immunodeficiency virus type 1 long terminal repeat. J. Neurovirol, 3 (supp 1): S28-S32.

Kuiken CL, Goudsmit J, Weiller GF, Armstrong JS, Hartman S, Portegies P, Dekker J, Cornelissen M (1995). Differences in human immunodeficiency virus type $1 \mathrm{~V} 3$ sequences from patients with and without AIDS dementia complex. J Gen Virol 76: 175-180.

Kurth J, Buzy JM, Lindstrom L, Clements JE (1996). In vivo transcriptional regulation of the human immunodeficiency virus in the central nervous system in transgenic mice. J Virol 70: 7686-7694.

Lenz J, Celander D, Crowther RL, Patarca R, Perkins DW, Haseltine WA (1984). Determination of the leukaemogenicity of a murine retrovirus by sequences within the long terminal repeat. Nature 308: $467-470$.

Li Y, Hui H, Burgess CJ, Price RW, Sharp PM, Hahn BH, Shaw GM (1992). Complete nucleotide sequence, genome organization, biological properties of human immunodeficiency virus type 1 in vivo: evidence for limited defectiveness and complementation. J Virol 66: $6587-6600$.

Liu ZQ, Wood C, Levy JA, Cheng-Mayer C (1990). The viral envelope gene is involved in macrophage tropism of a human immunodeficiency virus type 1 strain isolated from brain tissue. J Virol 64: 61486153.

Lu Y, Touzjian N, Stenzel M, Dorfman T, Sodroski JG, Haseltine WA (1990). Identification of cis-acting repressive sequences within the negative regulatory element of human immunodeficiency virus type 1 . $J$ Virol 64: $5226-5229$.

Masliah E, Achim CL, Ge N, DeTeresa R, Terry RD, Wiley CA (1992). Spectrum of human immunodeficiency virus-associated neocortical damage. Ann Neurol 32: 321-329.

McArthur JC, Selnes OA, Glass JD, Hoover DR, Bacellar $\mathrm{H}$ (1994). HIV dementia: incidence and risk factors. In HIV, AIDS and the Brain. Price RW and Perry SW (eds). Raven Press, Ltd., New York. pp251-272 
McNearney T, Hornickova Z, Templeton A, Birdwell A, Arens M, Markham R, Saah A, Taner L (1995). Nef and LTR sequence variation from sequentially derived human immunodeficiency virus type 1 isolates. Virology 208: $388-398$.

Michael NL, D'Arcy L, Ehrenberg PK, Redfield RR (1994). Naturally occurring genotypes of the human immunodeficiency virus type 1 terminal repeat display a wide range of basal and tat-induced transcriptional activities. J Virol 68: $3163-3174$.

Monken CE, Wu B, Srinivasan A (1995). High resolution analysis of HIV-1 quasispecies in the brain. AIDS 9: $345-349$

Myers G, Korber B, Hahn B, Jeang K-T, Pavlakis G, Meicors J, McCutchan F, Henderson L (eds). (1995). Human Retoviruses and AIDS 1995 Los Alamos National Laboratory, Theoretical Biology and Biophysics. Los Alamos, New Mexico.

Navia BA, Jordan BD, Price RW (1986). The AIDS dementia complex: I. clinical features. Ann Virol 19: $517-524$.

Nuovo GJ, Gallery F, MacConnell P, Braun A (1994). In situ detection of PCR-amplified HIV-1 nuclei acids and tumor necrosis factor alpha RNA in the central nervous system. Am J Pathol 144: 659-666.

O’Brien WA, Koyanagi Y, Namazie A, Zhao J, Diagne A, Idler K, Zack JA, Chen ISY (1990). HIV-1 tropism for mononuclear phagocytes can be determined by regions of gp120 outside the CD4-binding domain. Nature 348: $69-73$.

Orchard K, Perkins N, Chapman C, Harris J, Emery V, Goodwin G, Latchman D, Collins M (1990). A novel T-cell protein which recognizes a palindromic sequence in the negative regulatory element of the human immunodeficiency virus long terminal repeat. I Virol 64: $3234-3239$.

Pang S, Vinters HV, Akashi T, O'Brien WA, Chen ISY (1991). HIV-1 env sequence variation in brain tissue patients with AIDS-related neurologic disease. $J$ Acquir Immun Defic Syndr 4: 1082-1092.

Poliquin L, Bergeron D, Fortier J, Paquette Y, Bergeron R, Rassart E (1992). Determinants of thymotropism in Kaplan radiation leukemia virus and nucleotide sequence of its envelope region. J Virol 66: 51415146

Pomerantz RJ, Feinberg MB, Andino R, Baltimore D (1991). The long terminal repeat is not a major determinant of the cellular tropism of human immunodeficiency virus type 1. J Virol 65: 10411045.

Portis JL, Czub S, Garon CF, McAtee FJ (1990). Neurodegenerative disease induced by the wild mouse ecotropic retrovirus is markedly accelerated by long terminal repeat gag-pol sequences from nondefective friend murine leukemia virus. J Virol 64: $1648-1656$.

Power C, McArthur JC, Johnson RT, Griffin DE, Glass JD, Perryman S, Chesebro (1994). Demented and nondemented patients with AIDS differ in brainderived human immunodeficiency virus type 1 envelope sequences. J Virol 68: 4643-4649.

Resnick L, Berger JR, Shapshak P, Tourtelotte WW (1988). Early penetration of the blood brain barrier by HIV. Neurology 38: 9-14.
Rosen CA, Haseltine WA, Lenz J, Ruprecht R, Cloyd MW (1985). Tissue selectivity of murine leukemia virus infection is determined by long terminal repeat sequences. J Virol 55: 862-866.

Rosen CA, Sodroski JG, Haseltine (1985). The location of cis-acting regulatory sequences in the human $\mathrm{T}$ cell lymphotrophic virus type III long terminal repeat. Cell 41: $813-823$

Saito Y, Sharer LR, Epstein LG, Michaels J, Mintz M, Louder M, Golding K, Cvetkovich TA, Blumberg BM (1994). Overexpression of nef as a marker for restricted HIV-1 infection of astrocytes in postmortem pediatric central nervous tissues. Neurology 44: $474-481$

Saitou N, Nei M (1987). The neighbor-joining method: a new method for reconstructing phylogenetic trees. Molec Biological Evolution 4: 406-425.

Sharer LR (1992). Pathology of HIV-1 infection of the central nervous system. A review. J Neuropathol Exp Neurol 51: 3-11.

Sharpless NE, O’Brien WA, Verdin E, Kufta CV, Chen ISY, Dubois-Dalcq M (1992). Human immunodeficiency virus type 1 tropism for brain microglial cells is determined by a region of the env glycoprotein that also controls macrophage tropism. J Virol 66: $2588-2593.2$

Shimizu NS, Shimizu NG, Takeuchi Y, Hoshino H (1994). Isolation and characterization of human immunodeficiency virus type 1 variants infectious to brain-derived cells: detection of common point mutations in the $\mathrm{V} 3$ region of the env gene of the variants. J Virol 68: 6130-6135.

Shioda T, Levy JA, Cheng-Mayer C (1991). Macrophage and $\mathrm{T}$ cell-line tropisms of HIV-1 are determined by specific regions of the envelope gp120 gene. Nature 349: $167-169$

Small JA, Bieberich C, Ghotbi A, Hess J, Scangos GA, Clements JE (1989). The visna virus long terminal repeat directs expression of a reporter gene in activated macrophages, lymphocytes, and the central nervous systems of transgenic mice. J Virol 63: 18911896.

Takahashi K, Wesselingh SL, Griffin DE, McArthur JC, Johnson RT, Glass JD (1996). Localization of HIV-1 in human brain using polymerase chain reaction/in situ hybridization and immunocytochemistry. Ann Neurol 39: $705-711$.

Tillmann M, Krebs FC, Wessner R, Pomeroy SM, Goodenow MM, Wigdahl B (1994). Neuroglialspecific factors and the regulation of retrovirus transcription. Advances in Neuroimmunology 4: $305-318$.

Tornatore C, Chandra R, Berger JR, Major EO (1994). HIV-1 infection of subcortical astrocytes in the pediatric central nervous system. Neurology 44: $481-487$.

Watkins BA, Dorn HH, Kelly WB, Armstrong RC, Potts BJ, Michaels F, Kufta CV, Dubois-Dalcq M (1990). Specific tropism of HIV-1 for microglial cells in primary human brain cultures. Science 249: 549553. 
Weiser B, Peress N, La Neve D, Eilbott DJ, Seidman R, Burger $H$ (1990). Human immunodeficiency virus type 1 expression in the central nervous system correlates directly with extent of disease. Proc Natl Acad Sci USA 87: 3997 - 4001 .

Wiley CA, Baldwin M, Achim CL (1996). Expression of HIV regulatory and structural mRNA in the central nervous system. AIDS 10: 843-847.

Wiley CA, Schrier RD, Nelson JA, Lampert PW, Oldstone MBA (1986). Cellular localization of human immunodeficiency virus infection within the brains of acquired immune deficiency syndrome patients. Pro Natl Acad Sci USA 83: 7089-7093.
Yuen PH, Tzeng E, Knupp C, Wong PKY (1986). The neurovirulent determinants of ts1, a paralytogenic mutant of moloney murine leukemia virus TB, are localized in at least two functionally distinct regions of the genome. J Virol 59: 59-65.

Zeichner SL, Hirka G, Andrews PW, Alwine JC (1992). Differentiation-dependent human immunodeficiency virus long terminal repeat regulatory elements active in human terarocarcinoma cells. J Virol 66: 22682273. 